\title{
EDUCAÇÃO E CIDADANIA EM TRÊS EIXOS: ENQUANTO VA- LOR ECONÔMICO, GNOSIOLÓGICO E ÉTICO POLÍTICO
}

\author{
EDUCATION AND CITIZENSHIP IN THREE AREAS: as economic value, gnosio- \\ logical and political ethical
}
EDUCACIÓN Y CIUDADANÍA EN TRES ÁREAS: como valor económico, gnoseológi- ca y ética política

\author{
Lilian Tatiane Cândia de Oliveira \\ Professora Mestra do Centro Universitário da Grande Dourados (UNIGRAN). \\ Doutoranda em Educação pela Universidade Estadual de Maringá (UEM). \\ lilian.candia@hotmail.com \\ Maria Aparecida Cecílio \\ Professora Doutora da Universidade Estadual de Maringá (UEM). \\ maacecilio@hotmail.com
}

\begin{abstract}
RESUMO: A cidadania na Constituição Federal brasileira compõe um dos princípios fundamentais do Estado Democrático de Direito. No Art. 205 consta que a educação deve visar o pleno desenvolvimento da pessoa e seu preparo para o exercício da cidadania, a partir desse pressuposto, toda a legislação educacional é desenvolvida. Contudo, ao consultar a literatura especializada percebemos que ao longo de seu processo histórico, a palavra "cidadania" tem sido utilizada com diversos significados, inclusive na defesa de argumentos antagônicos. Assim, este estudo de cunho qualitativo, objetiva analisar três dos principais sentidos utilizados para a compreensão da palavra cidadania: cidadania enquanto valor econômico; valor gnosiológico e valor ético-político. A discussão textual evidencia que esses três significados estão presentes no cotidiano e na política educacional.
\end{abstract}

PALAVRAS-CHAVE: Política educacional. Cidadania econômica. Cidadania gnosiológica. Cidadania ética-política.

ABSTRACT: The citizenship in the Constitution is one the fundamental principles of the democratic rule of law. Article 205 states that education should aim at the full development of the person and his preparation for the exercise of citizenship, from this assumption, all educational legislation is developed. However, when we consults the specialized literature, we realize that throughout history process, the word "citizenship" has been used with various meanings, including the defense arguments antagonistic. Thus, this qualitative research, analyzes three major directions used for the understanding of the word citizenship: citizenship as economic value, value epistemological and ethical-political value. The textual discussion shows that these three meanings are present in daily life and in education policy.

KEYWORDS: Educational policy. Economic citizenship. Citizenship epistemological. Ethical and political citizenship.

RESUMEN: La ciudadanía en la Constitución Federal de Brasil constituye uno de los principios fundamentales del Estado democrático. En el Art. 205 establece que la educación debe tener como objetivo el pleno desarrollo de la persona y su preparación para el ejercicio de la ciudadanía, a partir de ese supuesto se desarrolla toda la legislación educativa. Sin embargo, cuando se hace referencia a la literatura nos dimos cuenta de que a lo largo de su proceso histórico, la palabra "ciudadanía" se ha utilizado con significados diferentes, incluyendo la defensa de argumentos opuestos. Este estudio de naturaleza cualitativa, tiene como objetivo analizar a tres de los principales sentidos utilizados para la comprensión de la palabra ciudadanía: la ciudadanía como valor económico; valor gnoseológico y valor ético-político. La discusión del texto muestra que estos tres significados están presentes en la vida cotidiana y en la política educativa.

PALABRAS CLAVE: Política educativa. Ciudadanía econômica. Ciudadanía epistemológica. Ciudadanía ética política.

$\overline{\text { Artigo recebido em maio de } 2015}$

Aprovado em julho de 2015

Cad. Pes., São Luís, v. 22, n. 2, mai./ago. 2015 


\section{1 | INTRODUÇÃO}

A cidadania compõe os princípios fundamentais do Estado Democrático de Direito, juntamente com a soberania, dignidade da pessoa humana, os valores sociais do trabalho e livre iniciativa, e pluralismo político. A Constituição Federal (1988) trouxe para a escola a responsabilidade de desenvolver a gestão democrática como mola propulsora da formação para a cidadania. Fato que possibilitou maior entendimento da cidadania numa perspectiva política, ultrapassando a perspectiva de uma cidadania distanciada da discussão e interação da vida social (Art. 205).

Em relação à Política Educacional, desde as teorias tradicionais até as da contemporaneidade, todas afirmam que o objetivo da educação é a formação do cidadão. Na Lei de Diretrizes e Bases da Educação Nacional o preparo para o exercício da cidadania é reiterado ao longo da normativa (nos Art. 2; 22; 35; 36). Mais recentemente, o Conselho Nacional de Educação (tendo como referência os dispositivos legais da Declaração Universal dos Direitos Humanos de 1948, da Declaração das Nações Unidas sobre a Educação e Formação em Direitos Humanos; do Programa Mundial de Educação em Direitos Humanos (PMEDH 2005/2014), do Plano Nacional de Educação em Direitos Humanos (PNEDH/2006); do Programa Nacional de Direitos Humanos (PNDH-3/2009) traçou os pilares de Diretrizes Nacionais para a Educação em Direitos Humanos (BRASIL, 2012) que devem ser observadas por todos os sistemas de ensino e suas instituições (Educação Básica e Superior), o que ratifica a formação para a cidadania.

Assim, preocupa-nos, primeiramente, compreender o significado do conceito de cidadania, antes mesmo, de pensar a "formação comum" necessária para o exercício da cidadania, conforme preconizado nas normativas já expostas. Sendo assim, este texto discute três eixos distintos que orientam o entendimento sobre conceito de cidadania, a saber: cidadania enquanto valor econômico; enquanto valor gnosiológico e enquanto valor ético político. Essas nomenclaturas, originalmente discutidas por Martins (2000a), são aqui objeto de reflexão. Num primeiro momento discutimos cidadania enquanto valor econômico que refere-se a sobreposição dos fatores econômicos às demais facetas sociais, no qual o cidadão é tratado como um cliente, um mero consumidor de serviços estatais. Num segundo momento ressaltamos a cidadania enquanto valor gnosiológico, no qual o cidadão conhece seus direitos e deveres, porém adota uma posição de passividade acrítica, não participa dos acontecimentos políticos, nem questiona seus princípios e finalidades; por último, expomos a cidadania enquanto valor ético-político, referente ao cidadão que se lança na luta política e por meio de uma participação consciente busca o fortalecimento e ampliação de seus direitos, e apresentamos as considerações finais.

\section{2 | CIDADANIA ENQUANTO VALOR ECONÔMICO'1}

Destacamos a cidadania enquanto valor econômico caracterizada pela sobreposição das questões econômicas em relação às demais facetas sociais, o que reduz o cidadão a um mero cliente, consumidor dos serviços Estatais. A cidadania em seu sentido democrático tem como finalidade a promoção da igualdade de direitos diante da lei, bem como, igualdade de participação política e condições socioeconômicas básicas como eixos que promovem a dignidade humana. Contudo, na dimensão do valor econômico esse encadeamento é reduzido, provocando uma "mutilação de cidadania", ainda que na defesa explícita de seu sentido universal.

\footnotetext{
${ }^{1}$ Esse subtítulo refere-se ao recorte e aprimoramento do trabalho apresentado em forma de Comunicação Oral no VII Simpósio Internacional: O Estado e as Políticas Educacionais no Tempo Presente, realizado em Uberlândia/MG.
} 
Assim, discutimos a cidadania enquanto valor econômico, condicionada por contextos do modo de produção e força de trabalho, considerando a educação como eixo transversal. Tomamos como base a afirmação de Marshall (1967) em que a cidadania é o ato de participar da vida política garantindo-se o mínimo de alcance dos direitos civis, políticos e sociais, todavia, abordando-se a participação da/na vida social que - pressupõe direitos e deveres - é muito delicado dar-se por universalizado o que se toma por "parte" ou mínimo a ser "oferecido", dado o sentido de totalidade que a cidadania propriamente dita evoca.

No mundo em que a renda dos quinhentos bilionários mais ricos, supera a dos quatrocentos e dezesseis milhões de pessoas mais afetadas pela pobreza no planeta (PNUD, 2007), há que se problematizar o olhar fragmentado e fragmentário sobre o conceito de cidadania que, o reduz a medidas de varejo tirando de foco ou marginalizando a desigualdade social. Um ponto que favorece a compreensão desse olhar, considerando a realidade brasileira, pode ser observado em meio ao processo de reestruturação produtiva e as exigências de formação de uma tipologia de cidadania pertinente que pudesse acompanhar as mudanças no âmbito do mercado (LIMA, 2012), demandadas pelo movimento do capital.

Esse movimento e as suas respectivas mudanças, tem como cerne as novas formas de reprodução do capital caracterizada por elevado investimento financeiro, mundialização e novos arranjos de acumulação capitalista a partir da reestruturação das bases produtivas (toyotismo), pautadas em inovações tecnológicas e flexibilização de todos os setores da produção, inclusive dos trabalhadores. Tais transformações, de acordo com Netto (2004) engendradas pela ofensiva do capital produziram uma reorganização dos Estados que culminou em um novo estágio do capitalismo global, na utilização de estratégias como: privatizações; políticas de ajuste financeiro e tributário; refilantropização da assistência; flexibilização e diminuição do papel do Estado na regulação das relações capital/trabalho e econômico/indutor.

Esse padrão possui características muito peculiares:

[...] marcada por um confronto direto com a rigidez do fordismo. Ela se apóia na flexibilidade dos processos de trabalho, dos mercados de trabalho dos produtos e padrões de consumo. Caracteriza-se pelo surgimento de setores de produção inteiramente novos, novas maneiras de fornecimento de serviços financeiros, novos mercados e, sobretudo, taxas altamente intensificadas de inovação comercial, tecnológica e organizacional. [...] permitem que os empresários exerçam pressões mais fortes de controle do trabalho sobre uma força de trabalho de qualquer maneira enfraquecida por dois surtos selvagens de deflação, força que viu o desemprego aumentar nos países capitalistas avançados para níveis precedentes no pós-guerra. (HARVEY, 2000, p. 140).

Nesse sentido, observa-se que as empresas têm buscado estratégias que venham atender as exigências da economia globalizada, adotando equipamentos tecnológicos que exigem um novo tipo de trabalhador mais qualificado, com maior nível de escolaridade e que assuma mais responsabilidades, devendo estar mais comprometido com aquilo que a empresa objetiva. O perfil exigido pelas empresas é de um trabalhador que seja "criativo e responsável, saiba resolver problemas, trabalhar em equipe, lidar bem com constantes inovações tecnológicas e que seja portador de uma alta capacidade de abstração, que o predisponha a constante aprendizagem" (ZIBAS, 1997, p. 123). Este contexto exige a manipulação e o controle da subjetividade combinado a outros elementos, inclusive ideológicos, que enfraquecem o empoderamento dos sujeitos.

A exigência do capital, no que se refere ao perfil do trabalhador tem impacto direto nas políticas sociais, dentre elas a educação e concomitantemente infere na dimensão de formação e exercício da/para a cidadania, uma vez que "a nova configuração imposta pela ordem econômica mundial [...] 
exige do Brasil, igual rapidez e agilidade na adequação das políticas de formação de recursos humanos, como respostas as mudanças decorrentes da reestruturação produtiva" (BRASIL, 2004, p. 07).

Essas mudanças no mundo ou "mundos" do trabalho (HOBSBAWN, 2005) determinam as políticas de formação profissional, com influência nas políticas educacionais propiciando novas demandas para a escola. É a partir da evolução dos modos de produção capitalista "[...] na era da globalização que podemos compreender a constituição de um complexo ideológico que irá determinar as políticas de formação profissional, com seus conceitos significativos de empregabilidade e competência" (ALVES, 2007, p. 249). Essas mutações afetam a sociedade como um todo, principalmente ao embasarem as reformas Estatais. É o que destaca Lima (2012, p. 2) quando expõe que a década de 1990 foi marcada pela adoção dos pressupostos neoliberais que davam sustentação à reestruturação produtiva no governo $\mathrm{FHC}$ e a reforma do Estado. Essas ações culminaram em "[...] ordenamento substancial das políticas públicas para a educação brasileira, inclusive [...] acerca da 'inclusão social' de classes expropriadas e grupos étnicos à universidade e demais modalidades de ensino, como já vinha sendo arquitetado entre as décadas de 1980 e 1990."

Nesses reordenamento político/social, de regressão de direitos, de cidadania enquanto valor econômico, Martins (2000a) destaca o predomínio de duas principais características: o individualismo e a reificação. O primeiro torna as relações sociais individualizadas com finalidades voltadas ao particular, em que parece não haver espaço para ações que visem o bem-estar coletivo. $\mathrm{Na}$ reificação "[...] tudo o que tem dimensão social, cultural, ética, religiosa transforma-se em coisa a ser produzida, devidamente oferecida a um mercado e consumida por ele, tal como uma mercadoria qualquer, isto é, tudo se reifica, tudo se transforma em coisa" (MARTINS, 2000a, p. 5). Nesse sentido a cidadania é referenciada pela lógica da racionalidade econômica que torna a política social, e a educação dentre elas, como parte desse processo, na qualificação permanente de mão-de-obra para o atendimento das exigências do mercado.

Assim, o tom para a construção da cidadania em documentos oficiais e literatura de apoio foi forjado pelo mercado, logo, os interesses do capital para a formação do cidadão foram revestidos de "humanidade" pelas oportunidades geradas, sem colocar como ponto de discussão a formação para a consciência cidadã, a extinção da exclusão social e as desigualdades sociais como um todo. Nesse sentido, a cidadania foi e continua sendo delineada pelos eixos da reestruturação produtiva ou, nos termos de Mészáros $(2005,2006)$ pelo sociometabolismo do capital.

Neste cenário (que resulta em precariedade de trabalho e exclusão) forja-se o novo tipo de trabalhador embasado no modelo das competências em que os conhecimentos e habilidades apreendidos no contexto escolar devem ter uma utilidade prática e imediata, e devem estar vinculados aos objetivos e missão das empresas. De acordo com Alves (2007) a qualidade da formação do trabalhador é avaliada pelo seu fim último, ou seja, as competências e habilidades do trabalhador devem ser adequadas às necessidades da racionalização do sistema produtivo. $O$ que nos remete a reflexão sobre a formação desse trabalhador.

Tal formação que atenda as exigências do mercado é um dos pressupostos que desencadeia elaborações e reformulações diretas na Política Educacional, tornando-se mola propulsora das reformas educacionais (SILVA JUNIOR, 2002). Para entendermos com maior embasamento a afirmação anterior, destacamos que o governo de Fernando Henrique Cardoso alinhavou mudanças sociais em face de uma matriz política, teórica e ideológica, caracterizada pela dependência do capital internacional que culminou em um novo conteúdo histórico para a cidadania centrada no individualismo; competitividade; adaptação; trabalho degradado; enfraquecimento de instituições e organizações políticas de mediação entre Estado e sociedade e, finalmente, a incapacidade de reivindicação do cidadão trabalhador. 
As consequências para a formação humana, diante do que denomina ideologia da instrumentalidade, adaptação e consenso presentes na Educação Básica, em especial no Ensino Médio, levam os jovens a desacreditarem na escola enquanto meio para a ascensão social e inserção no mercado de trabalho. Kuenzer (2000) afirma que o então novo Ensino Médio teria uma nova abordagem que seria para a vida, entretanto evidencia que o cerne de seu desdobramento atende aos interesses da classe dominante que o apresenta como uma face de interesse universal, porém, a outra face é a expressão de uma concepção de educação orgânica ao modelo econômico em curso, ou seja, a versão nacional do processo globalizado de acumulação flexível.

Oliveira (2001) destaca que as mudanças ocorridas globalmente devido ao capitalismo, principalmente decorrentes da produção de caráter flexível afetaram diretamente a Educação Profissional e a Educação do Ensino Médio brasileiro. Tais modificações são responsáveis pela mudança da vida humana nos mais diversos aspectos, inclusive provocando a reformulação da estrutura política do Estado que busca melhorar a qualidade da mão de obra e propicia uma maior proximidade das modalidades educativas ao setor produtivo. Assim, nem o Ensino Fundamental, na qual a relação entre educação e trabalho é implícita e indireta (SAVIANI, 2007), nem a formação de professores (EVANGELISTA; SHIROMA, 2007) tem sido imunes a influência da cidadania enquanto valor econômico. A escola é entendida como um setor produtivo, a repetência é um desperdício, justificando-se, inclusive, a necessidade da política de aceleração de classes.

Mas, a despeito do quadro que parece fatalista, é nos enfrentamentos do jogo político-econômico que se torna possível as resistências e busca por uma escola que transcenda as expectativas do homem como ser que se autoproduz e que tem capacidade para aprender que a emancipação não é uma dimensão de constituição perene, mas um movimento constante entre justiça, legalidade e interesses diversos envolvidos. A cidadania forjada por uma educação voltada para o mercado reforça os seus sentidos como valor econômico, conduzido por um discurso de favorecimento de inserção social e melhoria do nível de qualidade da classe trabalhadora - destacando que a formação para a cidadania está sendo realizada, entretanto, de forma implícita, traz consigo interesses velados que não garantem a efetividade dos discursos explicitados em sentido pleno, uma vez que somente parcelas da dimensão da cidadania são colocadas em evidência.

E o restante? O restante a lógica capitalista coloca como parte da agenda para renegociação com "dados valores" que em nada modificam a estrutura social e ainda assim conseguem "vender" ideologicamente a visão de que as mudanças substanciais são realidades plenamente tangíveis no atual sistema. O espaço escolar é palco do processo contraditório da sociedade capitalista, condicionada e condicionadora da reprodução da sociedade burguesa e das suas próprias contradições classistas existentes nessa ordem, ou seja, a manutenção e reprodução da sociedade é o objetivo número um da escola no capitalismo. Nesse sentido, impõe-se a necessidade de se compreender a ruptura com tal estrutura como um importante componente na construção de uma nova sociedade e de uma nova escola.

Daí a necessidade de compreensão do processo de formação do estudante para o exercício da cidadania. Rememorando Mészáros (2005, p. 12) "[...] uma educação para além do capital deve, portanto, andar com mãos dadas com a luta por uma transformação radical do atual modelo econômico e político hegemônico". A educação que supere a cidadania enquanto valor econômico deve desenvolver uma ação que prioriza o desvelar do mundo, formando cidadãos que entendem o contexto social ao seu redor, para além das aparências. 


\section{3 | EDUCAÇÃO E CIDADANIA ENQUANTO VALOR GNOSIOLÓGICO}

A gnosiologia trata de uma parte dos estudos filosóficos que se debruçam sobre o conhecimento humano. A partir da junção dos termos gregos gnosis e logos que significam respectivamente, conhecimento e estudos tem-se a palavra gnosiologia, ou seja, a teoria do conhecimento, ato ou ação de conhecer. É preciso, inicialmente compreender que a cidadania em sentido puramente gnosiológico desvincula-se do sentido ontológico, ou noutros termos, não articula os acontecimentos do mundo real com reflexões mais aprofundadas sobre suas causas e consequências, sobre o que subjaz as políticas num sentido mais amplo e os direitos e deveres, num sentido mais restrito.

Enquanto valor gnosiológico refere-se ao cidadão que simplesmente conhece seus direitos e deveres, principalmente os relacionados ao consumo. Nesse, o indivíduo adota uma posição de passividade acrítica, não participa do processo de elaboração dos direitos e deveres nem questiona seus princípios e suas finalidades. Para Martins (2000a, p. 8) ao observar as mídias é possível perceber que a palavra cidadania está sendo utilizada como sinônimo de ter ou tomar conhecimento dos direitos e deveres. Também destaca que ocorre uma valorização de instituições ligadas a defesa dos direitos dos consumidores, o que possibilita o acionamento de diversas instâncias para efetivar os direitos relacionados ao consumo/mercado. Porém, "outros direitos do cidadão não contam com a mesma 'vontade política governamental' e 'amparo legal' para serem efetivados."

Ora, cidadania não pode ser reduzida a sua dimensão gnosiológica, em que simplesmente o conhecimento dos direitos e deveres seja suficiente, embora crucial para o exercício da cidadania, apenas conhecer não conduz à efetividade de qualquer ação que garanta a cidadania. O conhecimento é fundamental para qualquer cidadão, contudo, nem todos têm acesso ao conhecimento de seus direitos e deveres. Tal situação pode reduzir as recorrências próprias do exercício da cidadania, visto que:

[...] o indivíduo passivo respeita os direitos e deveres que lhes são impostos sem questionar seus princípios, suas finalidades, a que interesses eles servem, enfim, sem se envolver com a dinâmica sócio-política, econômica e cultural que os forjou e sedimentou na sociedade, tendo em vista uma determinada correlação de forças entre os grupos sociais. (MARTINS, 2000a, p. 9).

Nesse sentido, o cidadão sucumbe por não enfrentar e superar os desafios e obstáculos apresentados na realidade por dimensões hegemônicas. A submissão do cidadão, não é um processo natural, pelo contrário é um processo ideológico, promovido pela disputa entre classes antagônicas que compõe a sociedade. O compêndio da cidadania ao valor gnosiológico, por vezes, resume $o$ ato de participar da vida política, ao sentido restrito de cumprir o dever cívico no comparecimento às urnas nos processos eleitorais. Sem uma efetiva ação fiscalizadora e reivindicatória por parte dos eleitores, o isolado ato de votar, não garante cidadania. Essa compilação resulta na aceitação passiva dos direitos sem a devida consciência de que todos podem ser agentes de existência e fortalecimento desses. Nessa vertente gnosiológica, a cidadania resume-se a um conjunto de deveres com ausência da pedra basilar da sociedade democrática: 0 ato de participar da Pólis, de ser governo, de pressionar, de não caracterizar-se como meros receptores, mas sujeitos das conquistas sociais.

É preciso salientar que em muitas sociedades nem os direitos básicos são conhecidos, por isso, como ressalta Carvalho (2011, p. 210), a "[...] educação é o fator que mais bem explica o comportamento das pessoas no que se refere ao exercício dos direitos civis e políticos. Os mais 
educados se filiam mais a sindicatos, a órgãos de classe, a partidos políticos", o que revela a significativa contribuição da escolaridade na efetivação da cidadania. Ao considerar a hegemonia (predomínio ideológico dos valores e normas da burguesia sobre as classes subalternas) como foco de sua análise, Gramsci (1999) enfatizou o papel da superestrutura, composta pelo Estado e sociedade civil (conjunto das relações culturais e ideológicas, da vida intelectual e espiritual), na perpetuação das classes e ainda na limitação da formação da consciência de classe. Para Gramsci (1999) o Estado tem como parte de suas funções o estímulo ao conceito de realidade burguesa, ou noutros termos, a hegemonia superestrutural burguesa.

Segundo Carnoy (1990, p. 27) "[...] é o tratamento que Gramsci dá à hegemonia que explica o desenvolvimento (ou a falta de desenvolvimento) da consciência da classe trabalhadora" e acrescenta "[...] Gramsci eleva o pensamento do homem (a consciência) a um proeminente lugar na 'filosofia da práxis' [...] o controle da consciência é uma área de luta política tão ou mais importante do que o controle das forças de produção."

Assim, para Gramsci (1999, p. 29) a consciência se configura como arena de disputa entre as classes. É pela consciência que a superação da submissão, da passividade acrítica pode ocorrer, por meio de uma organização da classe trabalhadora na disseminação de uma nova cultura hegemônica. "[...] Essa hegemonia proletária confrontaria a hegemonia burguesa em uma guerra de posições [...] até que a nova superestrutura tivesse cercado a antiga, incluindo o aparelho de Estado." Considerando os encadeamentos ideológicos e hegemônicos constituídos no âmbito escolar, observamos que estes incluem os processos que delineiam a aquisição dos saberes e a relação entre professor e aluno, que se caracterizam como bases da formação intelectual e acarreta resultantes diferenciadas de conformação, resistência ou superação na sociedade de classes.

Para Arroyo (2010, p. 37) "a tese da imaturidade e do despreparo das camadas populares para a participação e para a cidadania é uma constante na história do pensamento e da prática política". Ressalta que a cidadania fora negada por longos períodos o que pode justificar o despreparo da população para o seu exercício. Expõe que é frequente a interpretação de que a cidadania é construída por "[...] intervenções externas, de programas e agentes que outorgam e preparam para o exercício da cidadania" (ARROYO, 2010, p. 83) e que a interpretação da construção da cidadania num processo imerso na própria prática social e política das classes, não é tão frequente. Para esse estudioso a cidadania é forjada na contradição da sociedade de classes, na luta, resistência, organização e reação a violência que a classe trabalhadora é submetida cotidianamente.

Essa luta social frequentemente é ocultada e reprimida como desordem, pois, para a burguesia o ideal democrático e de cidadania pode ser resumido ao atendimento dos direitos da população, porém, sem o processo de fortalecimento das camadas populares, sem a efetivação da cidadania propriamente dita. Embora seja possível observar que a educação não fora pensada para a cidadania nos termos de participação e fortalecimento democrático é das camadas populares, pensadas e tratadas como não cidadãs, que advêm as críticas mais contundentes sobre a relação educação-cidadania. Uma educação para a cidadania pressupõe espaços de democracia onde os sujeitos se percebem movimentando-se na história e com a história. Um dos pontos que pode favorecer esse movimento é a superação das formas de pensar os coletivos sociais, étnicos, raciais, dos campos e das periferias, romper com a perversidade segregadora da cidadania condicionada à educação e da condição de subcidadania e até de invisibilidade, subumanidade. Pois, quando se pensa que os cidadãos marginalizados são

[...] inexistentes se afirmam como existentes; frente a visão de ignorantes, irracionais se mostram pensantes, com suas visões de mundo de história; frente a visão de incultos mostram suas memórias e identidades culturais; frente a visão de atrasados, inconscien- 
tes, pré-políticos, acríticos, pré-cidadãos mostram-se coletivos, conscientes, sujeitos políticos, de ações políticas, frente à visão de reclusos, fora do território e da comunidade política, se mostram agentes de tensões políticas, desestabilizando as relações políticas republicano-democrático-cidadãs estabelecidas. Nesse processo se conformam, se afirmam, se mostram cidadãos já. (ARROYO, 2010, p. 94).

Assim, faz-se necessário pensar a relação educação-cidadania ao invés de educação para a cidadania, considerar a cidadania que reeduca a própria educação e o pensamento político-pedagógico.

\section{4 | EDUCAÇÃO E CIDADANIA ENQUANTO VALOR ÉTICO POLÍTICO}

Enquanto valor ético-político a cidadania tem em seu cerne a participação crítica e o cidadão como sujeito capaz a partir de sua ação consciente, forjar seu destino histórico. Na atualidade tem-se legalmente preconizado a possibilidade de participação, por meio dos direitos que garantem a liberdade civil, política e social. Porém, na concretude das relações sociais, essa possibilidade de participação nem sempre pode ser efetivada, uma vez que "[...] Só tem acesso efetivamente àquilo que está expresso nas leis e nas diversas declarações de direitos do qual o país é signatário uma minoria que, pelo privilégio econômico que dispõe, consegue efetivar aquilo que as determinações legais garantem abstratamente" (MARTINS, 2000a, p. 11).

Para Martins, garantir a real possibilidade de participação, só seria possível mediante a superação desse contexto no qual a maioria do coletivo social não está incluído. Outra condição para a participação é a igualdade, não somente legal, mas igualdade socioeconômica de acesso a bens materiais, "satisfação de necessidades da existência física, dos bens sociais, capazes de garantir o acesso as esferas de poder, bem como àqueles simbólicos, garantidores do acesso à cultura, incluindo aí o indispensável domínio da linguagem escrita" (MARTINS, 2000a, p. 12).

Para superar a situação abstrata de existência dos direitos, que não se materializam efetivamente, exige-se o acesso à informação e aos mecanismos institucionais que possibilitam a efetiva participação. Desse modo o conceito de cidadania "[...] não é um estado psíquico e mental de um indivíduo que conhece seus direitos e deveres e nem, muito menos, uma relação particular do indivíduo que consome serviços do Estado" (MARTINS, 2000a, p.13). O conceito amplo de cidadania enquanto valor ético político agrega empoderamento e participação junto aos direitos civis, políticos e sociais articulados com a posse dos bens materiais, simbólicos e sociais

[...] a formulação a que chegamos do conceito é: cidadania é a participação dos indivíduos de uma determinada comunidade em busca da igualdade em todos os campos que compõem a realidade humana, mediante a luta pela conquista e ampliação dos direitos civis, políticos e sociais, objetivando a posse dos bens materiais, simbólicos e sociais, contrapondo-se a hegemonia dominante na sociedade de classes, o que determina novos rumos para a vida da comunidade e para a própria participação. (MARTINS, 2000b, p. 58).

Ao se efetivar a cidadania enquanto valor ético-político concomitantemente se efetiva a práxis, entendida como um "grau de homogeneidade, de autoconsciência e de organização" da classe trabalhadora. Essa consciência é proveniente do entendimento e da passagem do "momento econômico" (reconhecimento dos encadeamentos das condições materiais) para o "ético-político" (GRAMSCI, 1999, p. 314-315; BUCI-GLUCKSMANN, 1990, p. 124-125). Para Coutinho (2003, p. 70) a atividade política reivindicatória e participativa incluem "todas as formas de práxis que superam a simples recepção passiva ou a manipulação dos dados imediatos da realidade, e que dirigem, conscientemente, ao contrário, para a totalidade das relações objetivas e subjetivas". 
Logo, a atuação participativa na sociedade transforma o homem e concomitantemente na sociedade, que pode culminar numa nova situação social, devido à projeção na luta política com intuito de transformar as estruturas e superestruturas produtoras e reprodutoras das desigualdades entre as classes.

Nesse mesmo sentido, Benevides (1996) expõe a necessidade da valorização das ações políticas no intuito de superação do termo cidadania para além das relações econômicas. Para ela, o sistema nacional de ensino tem como prerrogativa, ainda que abstrata, a educação do cidadão, às vezes como "mero ornamento retórico ou, então, confundida com um vago civismo ou "patriotismo', o qual, evidentemente, varia muito de acordo com as concepções dos principais dirigentes educacionais" (BENEVIDES, 1996, p. 224). Daí a necessidade de uma educação que forme para a cidadania, que Benevides denomina "ativa", cidadãos que participem, que têm capacidade de julgar e decidir, pois a falta a educação que não fomente a participação compromete o futuro da democracia. Contudo, Benevides destaca que esse tipo de cidadão nem sempre é o preferido pelos governantes.

A cidadania enquanto valor ético-político somente pode se materializar numa democracia que reconhece e possibilita o direito de vez, voz e voto para um sujeito concreto que produz e se autoproduz. Para Benevides (1996, p. 225) a democracia é "o regime político fundado na soberania popular e no respeito integral aos direitos humanos. Esta breve definição tem a vantagem de agregar democracia política e democracia social", assim, essa democracia requer que todos os cidadãos sejam capazes de pensar, e atuar efetivamente na elaboração e aplicação das políticas públicas e, além disso, de julgar os resultados dessas.

Mas, o que seria a educação para a democracia pela formação do cidadão ético-político ou ativo? Para Benevides (1996, 2007), a educação para a democracia postula duas perspectivas: formação sobre valores republicanos e democráticos; e ,para tomadas de decisões políticas. Os valores republicanos referem-se ao respeito às leis, respeito ao bem público, e responsabilidade no exercício do poder. Já os valores democráticos, são explicitados por Benevides como: virtude do amor a igualdade (repúdio a qualquer forma de privilégios); respeito integral aos direitos humanos (respeitando raça, etnia, sexo, instrução, credo, julgamento moral, opção política, situação social, traz implícito a solidariedade); e acatamento à vontade da maioria (com constante respeito aos direitos das minorias).

Essa formação pode ser desenvolvida a partir de três eixos:

a) formação intelectual e a informação;

b) educação moral;

c) educação do comportamento.

A primeira refere-se ao acesso a informações de diferentes áreas do conhecimento de modo que o cidadão tenha consciência para efetivar suas escolhas. A segunda, trata-se da conquista de corações e mentes por meio de "uma didática de valores que não se aprendem intelectualmente apenas, mas sobretudo, pela consciência ética, que é formada tanto de sentimentos quanto de razão" (BENEVIDES, 1996, p. 226). A última, educação do comportamento desde os anos iniciais para firmar nos comportamentos hábitos de tolerância, cooperação, subordinação do interesse pessoal ao coletivo, ao bem comum.

A educação para cidadania ativa prepara os cidadãos para (a partir do critério de justiça no respeito aos valores de liberdade, igualdade e solidariedade), o julgamento, para tomada de decisões políticas num ciclo de recorrência e em constante avivamento. No enfrentamento de problemas variados. Como já salientado, o exercício da cidadania enquanto valor ético-político requer conhecimentos referentes aos direitos e deveres e uma postura eminentemente política na defesa e ampliação dos direitos por meio das políticas públicas, daí a necessidade da consciência coletiva 
como instrumento não-linear do "contrato social" que, na atual estrutura social, embora não seja um eixo dominante, tem demonstrado presença e força no encaminhamento das políticas educacionais na perspectiva da construção cidadã com valor ético-político.

Essa construção cidadã por meio das políticas educacionais requer uma educação de qualidade, que de acordo com Paro (2000, p. 107) é pressuposto para os objetivos a serem alcançados por meio da educação. Daí a fundamental importância de abordar claramente o que se entende por "qualidade" na educação, uma vez que, esta se não bem explicitada e justificada "pode acontecer de, em acréscimo à não correspondência entre medidas proclamadas e resultados obtidos, estar-se empenhando na realização dos fins errados ou não inteiramente de acordo com o que se pretende."

Segundo Paro, ao discutir a educação de nível fundamental, sendo processo de atualização histórica do homem, deve pautar seus objetivos a partir da dimensão individual e social. A primeira "diz respeito ao provimento do saber necessário ao autodesenvolvimento do educando, dando-Ihe condições de realizar seu bem-estar pessoal e o usufruto dos bens sociais e culturais postos ao alcance dos cidadãos em síntese, trata-se do educar para o 'bem viver'" (PARO, 2000, p. 107). A segunda está ligada a formação do cidadão de forma que este possa contribuir com a sociedade, na construção de uma ordem social mais adequada à realização do 'viver bem' de todos, de modo que haja liberdade enquanto construção social. Nesse sentido, Paro explicita que se há o entendimento de que a democracia, num sentido mais elevado, medeia à construção e exercício da liberdade social, no intuito de propiciar meios para o entendimento, embasados nos valores construídos historicamente, entre grupos e pessoas, essa seria a dimensão social da escola que se caracterizaria como educação para a democracia.

A relação educação/democracia tem permeado os estudos de Paro, que ao finalizar no ano de 2007, o Relatório de pesquisa sob o título "A administração escolar e a condição política da educação"2, ressalta que a escola, por meio da formação dos alunos, não pode determinar o tipo de sociedade na qual vivemos, porém, não se pode menosprezar sua importância no que concerne a apropriação de valores e hábitos que propiciam condutas democráticas. Sendo necessário, nesse sentido, romper com a imposição de um ensino que não interessa ao estudante. Restando ao estudante apenas obedecer ao que é determinado pelo professor, independente de sua vontade, a escola fomenta a obediência e passividade que não tem compatibilidade com o exercício, numa sociedade democrática, de cidadãos autônomos, trabalhando valores que constituem indivíduos habituados a dominar ou a obedecer sem resistência. As práticas democráticas no ambiente escolar devem forjar os verdadeiros cidadãos que contribuam para uma sociedade mais justa e livre.

A escola democrática deve orientar-se por ações que propiciem a participação de todos nos processos decisórios. Porém, a escola básica, embora tenha avançado em questões democráticas, nos últimos anos, mantém características de instituição que não foi pensada para os objetivos de educação democrática:

Suas atividades-meio (processo pedagógico), como vimos, são organizados do ponto de vista da educação tradicional, que não oferece uma posição de sujeitos aos educandos; suas atividades-fim (direção, serviços, coordenação do trabalho etc.), por seu turno, também são estruturadas e desenvolvidas de forma a não oferecer oportunidades de decisão aos vários grupos interessados ou envolvidos no trabalho da escola. (PARO, 2007, p. 27).

\footnotetext{
${ }_{1}^{1}$ Desenvolvida no Departamento de Administração Escolar e Economia da Educação da Faculdade de Educação da Universidade de São Paulo, com financiamento parcial do CNPQ.
} 
De acordo com o Relatório, o objetivo final da educação democrática é o desenvolvimento da autonomia do aluno e a formação de personalidades humano-históricas. Assim, o poder, (no sentido de poder-fazer) e a participação efetiva do estudante nos processos decisórios, não deve ocorrer apenas na atuação em conselho de escola, grêmio estudantil, ou outra entidade que representa os alunos, porém, separada da atividade escolar cotidiana. Como parte inerente à educação o aluno deve exercitar o poder na prática escolar cotidiana.

A construção do cidadão tutelado e vinculado a certos interesses, valores e ideologias particularizadas, foi impulsionado pela tipologia histórica de escola pública no Brasil. Afonso e Ramos (2007) utilizam a nomenclatura cidadania restrita à lógica do Estado-nação para designar, em certo momento da história humana, situações e condições sócio-políticas em que se caracterizou uma cidadania não democrática ou autoritária, uma vez que os direitos legalmente constituídos e respeitados foram escassos ou constrangidos. No contexto de globalização e reformas educativas no qual os sistemas educativos são delineados a partir das mudanças do sistema capitalista, em que se observa a política educacional voltada ao atendimento das necessidades dos sistemas produtivos, nem sempre a cidadania como dimensão da consciência coletiva é privilegiada nos espaços escolares.

Afonso e Ramos (2007) afirmam que é nesse contexto que a cidadania democrática e a coesão social emergem contraditoriamente, principalmente porque a cidadania é considerada um antídoto para a crescente vulnerabilização neoliberal dos direitos sociais que aumentam a desigualdade e a exclusão social. Daí a necessidade de assumir a escola, espaço público de democracia e cidadania, como lugar de confronto de hegemonias. Embora seja perceptível que a racionalidade econômica influenciou a política educacional brasileira, não se pode ignorar a concepção social da educação, uma vez que o desenvolvimento da política educacional amplia as oportunidades de acesso à educação o que concomitantemente pode diminuir as desigualdades sociais e por essa razão, a educação também é promotora da cidadania.

Porém, a educação para a cidadania parece estar fragilizada, é o que demonstra Jacobi (2008), ao ressaltar que existe um distanciamento entre o poder centralizado e as realidades sociais que evidenciam os limites dos mecanismos formais, verticais, corporativos e clientelistas, que foram criados para permitir/impedir a participação dos cidadãos nos assuntos públicos. Por esse olhar, há urgente necessidade de a cidadania ser assumida como ponto central para a participação dos cidadãos em processos de tomadas de decisão de interesse público, seja no contexto das políticas educacionais, como nas demais políticas estruturais e infraestruturais. O principal desafio será o de fortalecer os espaços deliberativos e modernizar os instrumentos de gestão e de articulação. Assim, urge a necessidade de acesso às informações, principalmente às populações mais vulneráveis para fortalecer as práticas de formação da cidadania ética-política e propiciar maior engajamento em práticas corresponsabilizadas de gestão da coisa pública, que garantam a expressão e representação de interesses coletivos.

A educação transformadora promove a consciência do olhar do estudante, dos professores, aprimora os encaminhamentos para que as políticas educacionais manifestem a dimensão democrática inerente à cidadania e o reconhecimento de que todos são participantes de uma história construída por meio de vez, voz e voto e mais do que isso, os saberes que são adquiridos e desdobrados passam a ter outro sabor: uma ênfase na construção do homem como ator social e não como sujeito passivo que deve, simplesmente, consumir um conhecimento intelectual linearizado (LIMA, 2010). Eis o grande desafio, portanto: educação na e para a cidadania ética-política. 


\section{5 | CONSIDERAÇÕES FINAIS}

Discutimos os três eixos de significados da cidadania apontados por Martins (2000a) e buscamos evidenciar o quanto as marcas dessas tipologias estão presentes no cotidiano. Cidadania enquanto valor econômico é forjada na sobreposição dos fatores econômicos, na necessidade de mão de obra que atenda as exigências do capital, na formação para o consumo, no fetiche da mercadoria, entre outros que não puderam ser contempladas nessas poucas páginas. A cidadania enquanto valor gnosiológico, também tão presente em nosso cotidiano, que por vezes, mesmo tendo conhecimento de nossos direitos não somos capazes de exigi-lo, nossa cultura de passividade nos impede. Por vezes somos violados no atendimento de nossos direitos, na saúde, na assistência social, na previdência e até mesmo na educação, porém nem sempre os exigimos.

Contudo, nesse contexto aparentemente fatalista, vale ressaltar, que o princípio que serve como diretriz para a educação que contribua para a cidadania enquanto valor ético-político é a que possibilita o desenvolvimento de capacidades e da autonomia, em que os indivíduos sejam capazes de não se submetem a poderes estabelecidos sem um prévio julgamento. Contudo, como foi possível perceber a educação que propicia e efetiva a cidadania, ainda é o grande desafio da atualidade.

Os encaminhamentos por se construir não se remetem somente ao elencamento de políticas públicas que enfatizem a educação como uma das garantias do direito cidadão, também é verdadeira a vivência e o entendimento da cidadania como conquista e que, por meio da educação, os marcos sejam memoriais da mesma, na perspectiva de sua dimensão humana, democrática e universal. 


\section{Referências}

AFONSO, A. J.; RAMOS, E. L. V. Estado-nação, educação e cidadanias em transição. Revista Portuguesa de Educação, v. 20, n. 1, 2007. Disponível em: <http:// www.scielo.gpeari. mctes.pt/pdf/rpe/v20n1 /v20n1a04. pdf>. Acesso em: 25 de jun. 2012.

ALVES, G. Dimensões da reestruturação produtiva: ensaios de sociologia do trabalho. 2. ed. Londrina: Praxis; Bauru: Canal 6, 2007.

ARROYO, M. G. Educação e exclusão da cidadania. In: BUFFA, E.; ARROYO, M. G.; NOSSELLA, P. Educação e cidadania: quem educa o cidadão? 14. ed. São Paulo: Cortez, 2010.

BENEVIDES, M. V. M. Educação para a democracia. Lua Nova, n. 38, p. 223-237, 1996. Disponível em: < http://www.scielo.br/scielo.php?pid=S0102-644519960 00200011\&script=sci_arttext>. Acesso em: 23 set. 2012.

A questão social no Brasil: os direitos econômicos e sociais como direitos fundamentais, 2007. Disponível em: <http://www.hottopos.com/vdletras3/ vitoria. htm>. Acesso em: 30 out. 2012.

BUCI-GLUCKSMANN, C. Gramsci e o Estado: por uma teoria materialista da filosofia. Tradução Angelina Peralva. 2. ed. Rio de Janeiro: Ed. Paz e Terra, 1990. 499 p. (Pensamento Crítico, v. 39).

BRASIL. Constituição (1988). Constituição da República Federativa do Brasil. Brasília, DF: Senado Federal, 1988. Disponível em: < http://www.planalto.gov.br/ccivil_03/ constituicao/ConstituicaoCompilado.htm>. Acesso em: 22 out. 2011.

Lei n 9.394, de 20 de dezembro de 1996. Estabelece as Diretrizes e Bases da Educação Nacional. Diário Oficial da União. Brasília, DF, 23 dez. 1996. Disponível em: <http://www.planalto.gov.br/ccivil_03/leis/ L9394.htm>. Acesso em: 22 out. 2011.

Ministério da educação. Secretaria de Educação Média e Tecnológica. Ensino Médio-Políticas. Brasília, DF: MEC; SEMTEC, 2004. Disponível em: <http://portal.mec.gov.br/setec/arquivos/pdf/guia_orient. pdf >. Acesso em: 15 abr. 2011.

Resolução CNE/CP $n^{\circ} 1$, de 30 de maio de 2012. Estabelece Diretrizes Nacionais para a Educação em Direitos Humanos. Diário Oficial da União. Brasília, DF, 31 maio 2012. Seção 1, p. 48. Disponível em: <http://portal.mec.gov.br/index.php?option=com_content\&id=17810\&Itemid=866>. Acesso em: 22 out. 2011.

CARNOY, M. Educação, economia e Estado: base e superestrutura relações e mediações. 4. ed. São Paulo: Cortez; Autores Associados. 1990.
CARVALHO, J. M. Cidadania no Brasil: o longo caminho. Rio de Janeiro: Civilização Brasileira, 2011.

COUTINHO, C. N. O conceito de política nos Cadernos do cárcere. In: COUTINHO, C. N.; TEIXEIRA, A. de P. (Org.). Ler Gramsci, entender a realidade. Rio de Janeiro: Civilização Brasileira, 2003. p. 67-82.

EVANGELISTA, O; SHIROMA, E. O. Professor: protagonista e obstáculo da reforma. Educação \& Pesquisa, São Paulo, v. 33, n. 3, set./dez. 2007. Disponível em: <http://www.scielo.br/scielo.php?script=sci_arttext\&pi $d=$ S1517-97022007000300010\&lang=pt>. Acesso em: 18 mar. 2010.

GRAMSCI, A. Cadernos do cárcere: introdução ao estudo da filosofia: a filosofia de Benedetto Croce. Rio de Janeiro: Civilização Brasileira, 1999.

HARVEY, D. Condição pós-moderna. 9. ed. São Paulo: Loyola, 2000.

HOBSBAWM, E. J. Mundos do trabalho. São Paulo: Paz e Terra, 2005.

JACOBI, P. R. Estado e educação: o desafio de ampliar a cidadania. Educação em Revista, n. 31, p. 113-127, 2008. Disponível em: <http://www.scielo.br/ scielo.php? script=sci_arttext\&pid=S0104-40602008000100008\&la ng=pt>. Acesso em: 18 jun. 2012.

KUENZER, Z. A. O ensino médio agora é para a vida: entre o pretendido, o dito e o feito. Educação \& Sociedade, Campinas, v. 21, n. 70, abr. 2000. Disponível em: <http://www.scielo.br/scielo.php?pid=S0101$73302000000100003 \&$ script $=$ sci_arttext \&tlng=es $>$. Acesso em: 13 mar. 2010.

LIMA, P. G. Formação de professores: por uma ressignificação do trabalho pedagógico na escola. Dourados/MS: Editora da UFGD, 2010.

. Universidade brasileira numa perspectiva universal, humana e democrática. São Paulo: Annablume, 2012.

MARSHALL, T. H. Cidadania, classe social e status. Tradução Meton Porto Gadelha. Rio de Janeiro: Zahar Editores, 1967.

MARTINS, M. F. Uma "catarsis" no conceito de cidadania: do cidadão cliente à cidadania com valor ético-político. Revista de Ética, Campinas, v. 2, n. 2, jul./ dez. 2000a. Disponível em: <http://www.am.unisal.br/ graduacao/ped/pdf/2007/art_conceito_de_cidadania. pdf>. Acesso em: 10 jan. 2012. 
EDUCAÇÃO E CIDADANIA | Lilian Tatiane Cândia de Oliveira e Maria Aparecida Cecílio

\section{Referências}

. Ensino técnico e globalização: cidadania ou submissão? Campinas: Autores Associados, 2000b.

MÉSZÁROS, I. A educação para além do capital. São Paulo: Boitempo, 2005.

MÉSZÁROS, I. Para além do capital. São Paulo: Boitempo Editorial, 2006.

NETTO, J. P. Notas sobre a reestruturação do Estado e a emergência de novas formas de participação da sociedade civil. In: BOSCHETTI, I. et al. (Org.). Política social: alternativas ao neoliberalismo. Brasília: UnB, Programa de Pós-Graduação em Política Social, Departamento de Serviço Social, 2004.

OLIVEIRA, R. A divisão de tarefas na educação profissional brasileira. Cadernos de Pesquisa, São Paulo, n.112, mar. 2001. Disponível em: <http://www.scielo.br/ scielo.php?script=sci_arttext\&pid=S0100 -15742001000 100010\&lang=pt>. Acesso em: 13 mar. 2010.

PARO, V. H. Educação para a democracia: o elemento que falta na discussão da qualidade do ensino. In: REUNIÃO ANUAL DA ANPEd, 23., 2000, Goiânia. Anais eletrônicos... Goiânia: ANPED, 2000. p. 107-122. Disponível em: <http://www.anped.org.br/reunioes/23/ textos/0528t.PDF>. Acesso em: 17 maio 2012.

PARO, V. H. Educação como exercício do poder: implicações para a prática escolar democrática. 2007. Disponível em <https://www.google.com.br/url?sa=t\&rct=$j \& q=\&$ esrc $=s \&$ source $=$ web\&cd $=1 \&$ cad $=$ rja $\&$ ved $=0 C$ DIQFjAA\&url=http\%3A\%2F\%2Fwww.sindservsantos. org.br\%2Fimagens\%2Fupload\%2Fdocumento68. doc\&ei=UvNyUarXJ7OqOAGauYHYBQ\&usg=AFQjCNHDSTWICD6sw6PxWBWm_yV4pLTPOg\&sig2=ijtOq4HNawdH3QP7FRG0zQ\&bvm=bv.45512109,d. dmQ>. Acesso em: 14 de Mar. 2013.
PNUD. Relatório de Desenvolvimento Humano de 2007/2008. Combater as alterações climáticas: solidariedade humana num mundo dividido. Coimbra/Portugal: Gráfica de Coimbra, 2007. Disponível em: <http:// http://www.pnud.org.br/hdr/arquivos/RDHglobais/ hdr2007-8-portuguese.pdf>. Acesso em: 17 maio 2012.

SAVIANI, D. Trabalho e educação: fundamentos ontológicos e históricos. Revista Brasileira de Educação, Rio de Janeiro, v. 12, n. 34, jan./abr. 2007. Disponível em: <http://www.scielo.br/scielo.php?pid=\$1413-24782 $007000100012 \&$ script $=$ sci_arttext $\&$ tlng $=e m>$. Acesso em: 15 abr. 2010.

SILVA JUNIOR, J. R. Mudanças estruturais no capitalismo e a política educacional do governo FHC: o caso do ensino médio. Educação \& Sociedade, Campinas, v. 23, n. 80, set. 2002. Disponível em: <http://www.scielo. $\mathrm{br} / \mathrm{scielo}$.php?script=sci_arttext\&pid=S0101-733020020 08000011\&lang=pt >. Acesso em: 15 mar. 2010.

ZIBAS, D. M. L. O reverso da medalha: os limites da administração industrial participativa. In: CARLEIAL, L.; VALLE, R. (Org.). Reestruturação produtiva e mercado de trabalho no Brasil. São Paulo: Hucitec-Abet, 1997. p. 122-139. 